\title{
MECHANICAL PERFORMANCE OF COMPOSITE RETAINING AND PROTECTION STRUCTURE FOR SUPER LARGE AND DEEP FOUNDATION EXCAVATIONS
}

\author{
Zhen CUI ${ }^{1}$, Qimin $\mathrm{LI}^{1 *}$, Jian WANG ${ }^{2}$ \\ ${ }^{1}$ School of Water Resources and Environment, China University of Geosciences (Beijing), Beijing 100083, China \\ ${ }^{2}$ School of Civil Engineering, Southwest Jiaotong University, Chengdu 610031, China
}

Received 16 December 2018; accepted 12 March 2019

\begin{abstract}
The reliable retaining methods and a good stress system are the key to the success of super large and deep excavation engineering. In this paper, the deepest foundation pit in Hainan province is taken as an example. The method of mutual verification between in-situ monitoring and numerical simulation is adopted. The mechanical performance of composite retaining structure composed of reinforced concrete cast-in-situ soldier pile wall, diaphragm wall and prestressed anchor cable are studied. The interaction between the reinforced concrete cast-in-situ pile retaining structure at the upper part and the diaphragm wall retaining structure at the lower part is revealed, and the variation of internal forces of the diaphragm wall retaining structure in the time and space is demonstrated. And then the influence of insertion ratio and rigidity on the mechanical properties of diaphragm wall is discussed. Research shows, the range of interaction between the upper and lower retaining structures is limited. During the excavation process, the maximum bending moment of the diaphragm wall is always near the excavation surface, and the curvature of the bending moment curve decreases gradually with the increase of excavation depth and axial tension of anchor. When the insertion ratio of diaphragm wall increases, the maximum bending moment moves upward. With the rigidity of the diaphragm wall increases moderately, the bending moment of the retaining structure increases, but the lateral displacement decreases. The research results can provide theoretical basis and practical experience for the composite retaining structure design of super large and deep foundation excavations.
\end{abstract}

Keywords: super deep excavations, composite retaining structure, on-site monitoring, numerical simulation, mechanical effect, time effect, rigidity effect.

\section{Introduction}

Hainan is located in the southern tip of China and is the largest province in Chinese territorial area (including sea area). It is not only the main window facing Hong Kong, Macao, Taiwan and Southeast Asia, but also the central hub of the Maritime Silk Road. In recent years, with the rapid economic development of Hainan Province, various kinds of high-rise and super-high-rise buildings and large-scale infrastructure construction are booming. However, the foundation embedment depth of high-rise building shall satisfy the requirements for the ground bearing capacity, deformation and stability. In other words, the higher the building, the deeper its foundation. During the excavation process, the retaining structure is affected by ground surcharge, water and earth pressure, etc. The deeper the foundation pit is excavated, the more complicated the stress of the retaining structure is, and the greater the risk of the excavations engineering will be (Szepesházi, Mahler, \& Móczár, 2016; Liyanapathirana \& Nishanthan, 2016; Cheng et al., 2017; Lin, Liu, \& Zhou, 2015; Hyun, Hyung, \& Yeol, 2011; Li, Zhang, He, Huang, Cheng, \& Guo, 2017; Tan, Zhu, Peng, Karlsrud, \& Wei, 2017).

The key to ensure the safety of excavations is to obtain the internal force produced by the retaining structure during the excavation process and analyze its evolution characteristics. It is better to inversely calculate the bending moment of the retaining structure through the field measured data, and show a series of changes in the internal force of the retaining structure with the increase of the excavation depth of the foundation pit. At present, there are several methods for calculating the bending moment of

${ }^{*}$ Corresponding author. E-mails: qiminli@163.com, qiminli@cugb.edu.cn 
the retaining structure. For example, the bending moment of retaining structure is calculated by measuring the stress or strain of reinforcement at the site (Chen, Yang, Zhang, Wang, \& Ou, 2017). But there are few reports about the measured data of composite supporting structure for super deep excavations, to date, there has been little information about the field measured data of composite retaining structure of reinforced concrete cast-in-situ soldier pile, diaphragm wall and anchor cable. Take one more example, the actual bending moment of the retaining structure in the excavation process is estimated through fitting a curve to the inclinometer data with least square method. However, this method needs to fit the displacement curve and the load curve twice respectively, and the fitting error is large for the deep pit. When the natural spline method is used to fit the bending moment curve of the retaining structure, the bending moment value is often oscillated due to the error of the measured inclination value, and the fitting result is distorted. Based on the monitoring data, the smoothing spline method is used to fit the support structure curve (Ooi \& Ramsey, 2003), and the measurement error limit can be used to reduce the fitting error of the natural spline method, but the measurement error is difficult to estimate accurately.

In this project, the reliable composite retaining structure is designed for super large and deep excavations, and the rebar stress meters (RSMs) were installed in diaphragm wall. The method of mutual verification between in-situ monitoring data and finite element method PLAXIS is adopted. The evolution characteristics of the internal force of the composite retaining structure in time and space are discussed. The interaction between the upper and lower retaining structure are analyzed. The influence of retaining structure parameters on supporting performance is revealed. It provides basis for solving many problems of super large and deep excavations.

\section{Project overview}

\subsection{Architectural design}

The "Haikou tower" project is located in Haikou City, Hainan province. It consists of a super high-rise tower and two buildings, with a total construction area of $388,000 \mathrm{~m}^{2}$. Among them, the tower has 94 floors above ground and a building height of $428.3 \mathrm{~m}$. It is a landmark of Hainan Island, which integrates five-star hotels, SOHO-style apartments, boutique commercial buildings, high-end office buildings and sightseeing tours. The basement of the building is four-level, which are underground garage, boiler room, distribution room, air conditioning room, etc. The building is the highest building in Hainan and will provide working and living space for more than 20,000 people. Figure 1 shows the "Haikou Tower" architectural renderings.

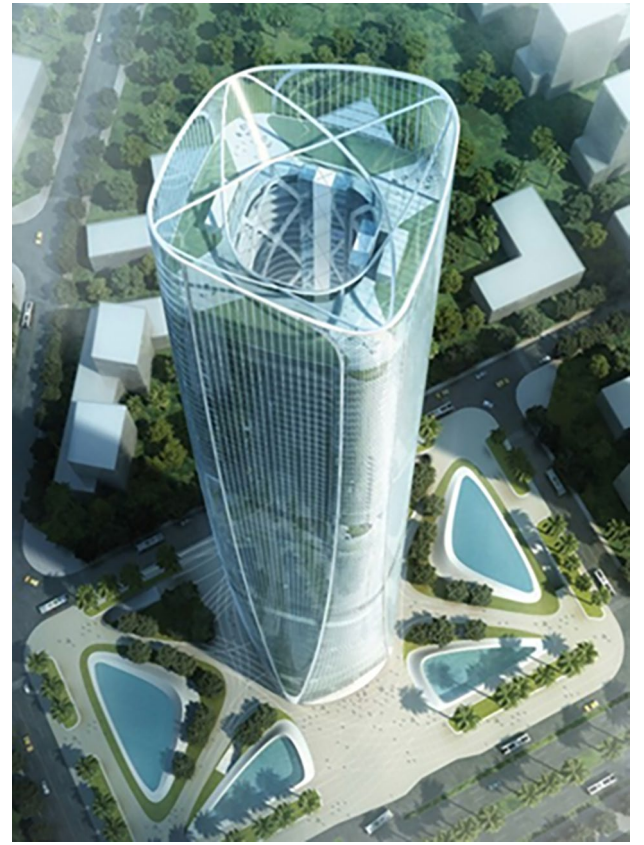

Figure 1. "Haikou Tower" architectural renderings

\subsection{Engineering geology and hydrogeological conditions}

The project is located in the Qiongbei Cenozoic fault basin, and the site soil is mainly sandy soil and cohesive soil. Table 1 presents the physical and mechanical parameters of site soil.

There are two layers of groundwater distributed in the site. The first aquifer mainly consists of pore phreatic water in coarse sand and silty sand. The source of recharge is mainly atmospheric precipitation and interlayer seepage. The thickness of the aquifer is large and the permeability is better. It belongs to the strong permeable stratum. The aquifer has a stable water level buried depth of 7.70 9.00 m. The second aquifer is pore confined water which is occurred in medium sand. The source of recharge is mainly interlayer percolation and underground runoff of basalt platform. The aquifer has good water permeability and belongs to a strong permeable layer. However, the second aquifer is deeply buried, which has little effect on the foundation construction and foundation excavation of the project.

\subsection{Design and construction of excavation}

The "Haikou Tower" foundation pit has a maximum length of $266.6 \mathrm{~m}$ in the east-west direction, a maximum width of $133.2 \mathrm{~m}$ in the north-south direction, a whole depth of $20.3 \mathrm{~m}$, and a depth of $25.4 \mathrm{~m}$ in the tower area, which is the deepest excavation in Hainan Province. The foundation pit covers an area of about $30,000 \mathrm{~m}^{2}$, and the amount of earthwork volume alone reaches $700,000 \mathrm{~m}^{3}$. 
Table 1 . The physical and mechanical parameters of field soil

\begin{tabular}{|c|c|c|c|c|c|c|c|c|c|}
\hline $\begin{array}{c}\text { Strata } \\
\text { number }\end{array}$ & Soils name & State & $\begin{array}{l}\text { Thickness } \\
\text { (m) }\end{array}$ & $\begin{array}{c}\text { Gravity } \\
\text { density } \\
\left(\mathrm{kN} / \mathrm{m}^{3}\right)\end{array}$ & $\begin{array}{c}\text { Permeability } \\
\text { coefficient } \\
(\mathrm{m} / \mathrm{d})\end{array}$ & $\begin{array}{l}\text { Compression } \\
\text { modulus } \\
(\mathrm{MPa})\end{array}$ & $\begin{array}{l}\text { Poisson's } \\
\text { ratio }\end{array}$ & $\begin{array}{c}\text { Cohesion } \\
\text { strength } \\
(\mathrm{kPa})\end{array}$ & $\begin{array}{l}\text { Internal } \\
\text { friction } \\
\text { angle }\left(^{\circ}\right)\end{array}$ \\
\hline (1) & $\begin{array}{l}\text { Artificial } \\
\text { fill }\end{array}$ & Loose & $0.5-2.8$ & 20 & 0.3 & 10.13 & 0.30 & 10 & 10 \\
\hline (2) & $\begin{array}{l}\text { Medium } \\
\text { sand }\end{array}$ & Slightly dense & $1.2-6.1$ & 19.9 & 0.3 & 9.54 & 0.25 & 12.5 & 32.3 \\
\hline (3) & Clay & Plastic & $0.8-9.7$ & 18.3 & 0.001 & 6.42 & 0.35 & 44.2 & 8.1 \\
\hline (4) & $\begin{array}{l}\text { Coarse } \\
\text { sand }\end{array}$ & $\begin{array}{l}\text { Saturated } \\
\text { medium } \\
\text { dense } \\
\end{array}$ & $1.4-12.4$ & 20.5 & 1.48 & 10.65 & 0.23 & 5 & 30.3 \\
\hline (5) & Silty sand & $\begin{array}{l}\text { Saturated } \\
\text { medium } \\
\text { dense }\end{array}$ & $4.7-16.4$ & 19.9 & 0.915 & 14.95 & 0.20 & 10 & 28.2 \\
\hline (6) & Clay & Plastic & $2.9-13.6$ & 18.1 & 0.001 & 7.59 & 0.35 & 36.1 & 9.7 \\
\hline (7) & Silty clay & Plastic-hard & $105-110$ & 19.3 & 0.001 & 10.62 & 0.28 & 70.1 & 26 \\
\hline (8) & $\begin{array}{l}\text { Medium } \\
\text { sand }\end{array}$ & Dense & - & & & & & & \\
\hline
\end{tabular}

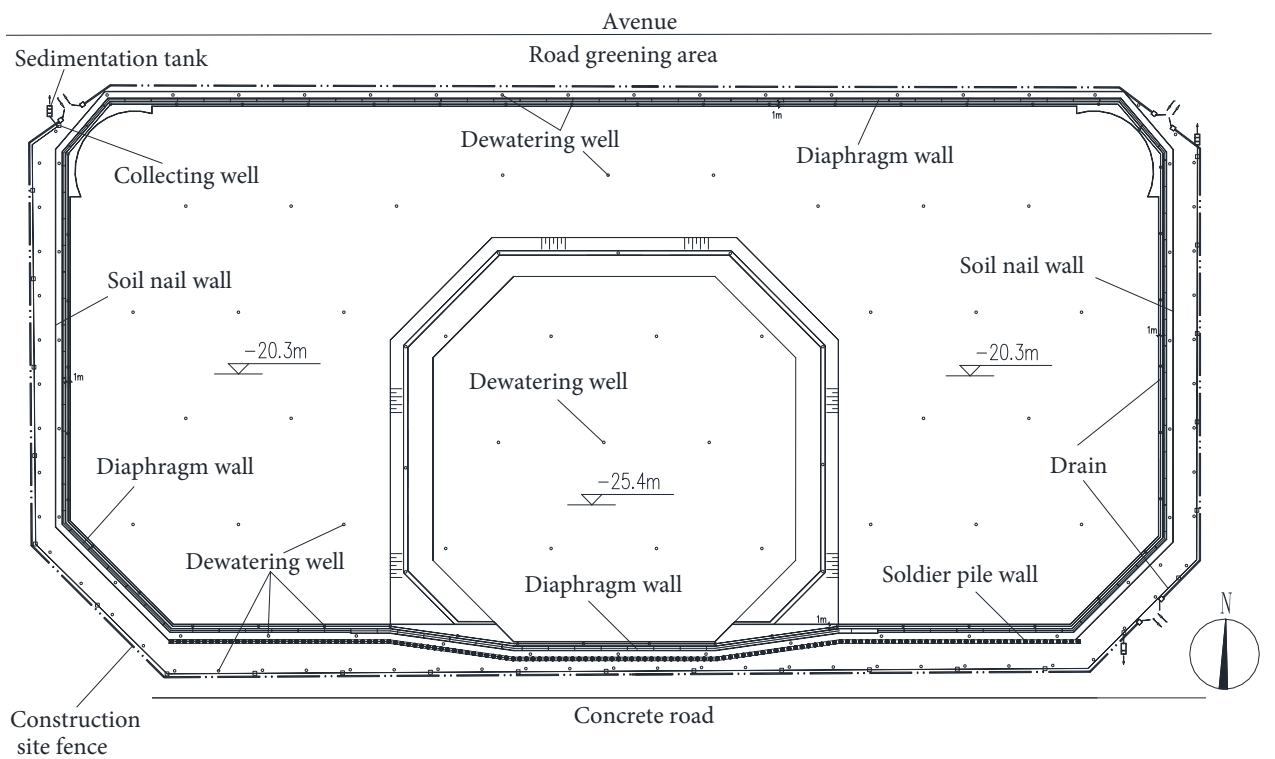

Figure 2. The layout of the excavation engineering

The east, west and north sides of the foundation pit are supported by soil nailing wall (supporting height $6.5 \mathrm{~m}$ ), diaphragm wall (thickness $800 \mathrm{~mm}$ ) and anchor cable. The south tower area is supported by reinforced concrete castin-site soldier piles ( $11.5 \mathrm{~m}$ in length, $800 \mathrm{~mm}$ in diameter), diaphragm wall (1000 $\mathrm{mm}$ in thickness) and anchor cables. Figure 2 presents the layout of the excavation engineering. Figure 3 shows the longitudinal section of the composite retaining and protection structure at the south side of the excavation. The safety grade of the excavation is grade one, and the design workable life of the retaining and protection structure is 2 years.
The construction of the Haikou tower project was started in June 2015. The main construction procedures for the excavation and support of the foundation pit are as follows: (1) Construction of reinforced concrete castin-situ soldier piles - Construction of capping beam of retaining soldier piles - Foundation pit is excavated to $6.5 \mathrm{~m}$ - Construction of soil nailing wall - Construction of shotcrete surface. (2) Construction of diaphragm wall Layered excavation - Layered anchor cable installation. Figure 4 presents construction photo of the composite retaining and protection structure at the south side of the excavation. 


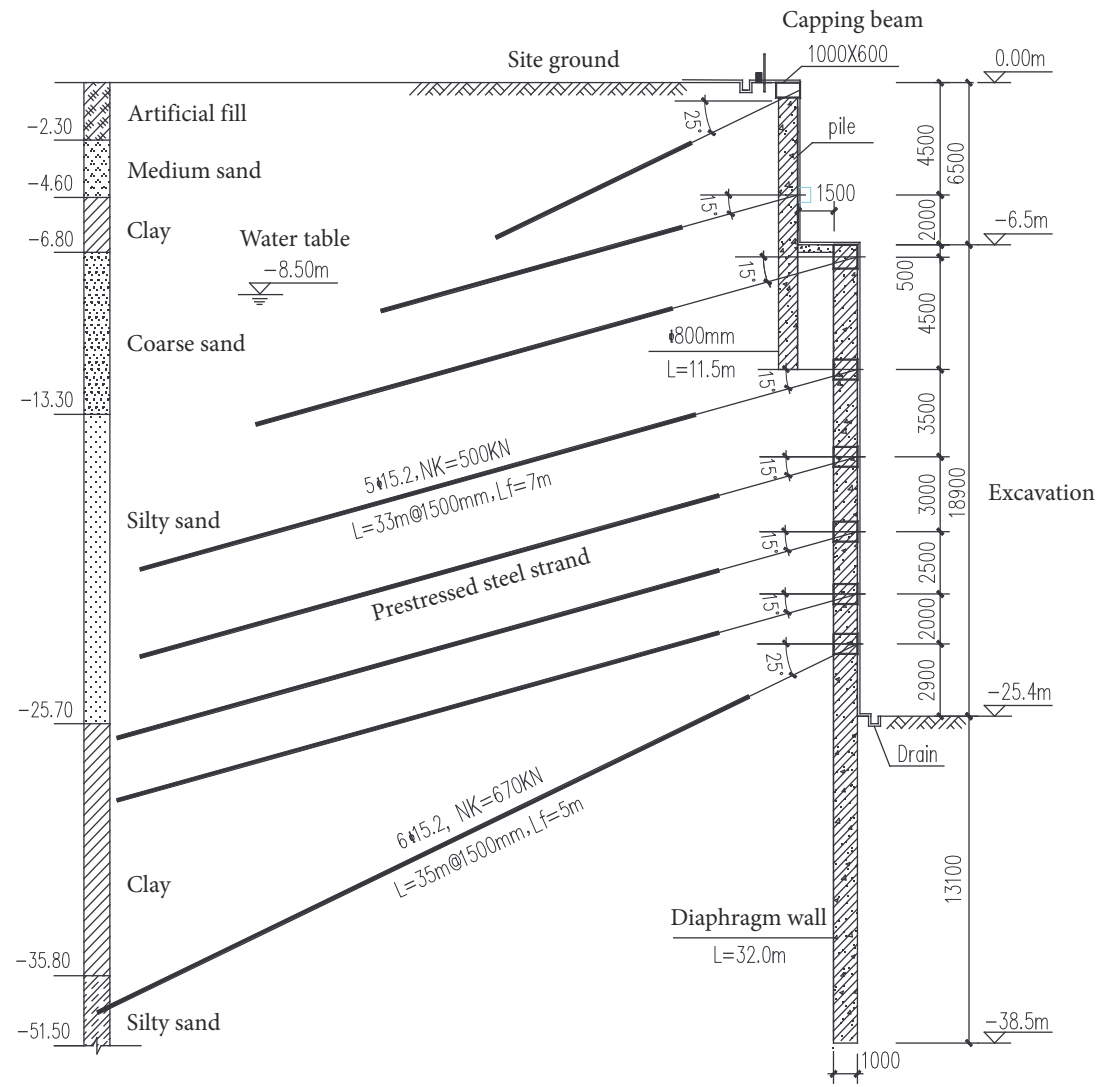

Figure 3. Longitudinal section of the composite retaining and protection structure at the south side of the excavation

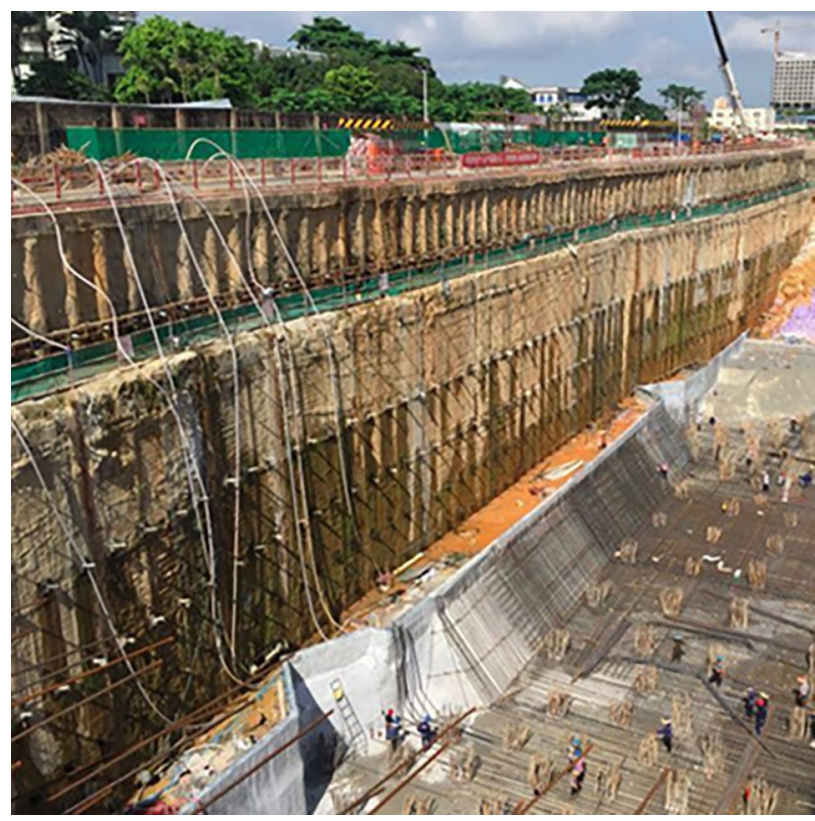

Figure 4. Construction photo of the composite retaining and protection structure at the south side of the excavations

\section{Construction monitoring}

\subsection{Monitoring principle}

In this project, rebar stress meters (RSMs) were used to monitor the bending moment variation of the retaining structures. The rebar stress meters were installed on the steel bars of the tension side and the pressure side of the diaphragm wall respectively. The bending moment can be calculated by the stress value, which is measured by rebar stress meters. The conversion of the bending moment value at the cross section of the diaphragm wall is as follows:

$$
M=\frac{E_{c}}{E_{s}} \cdot \frac{I_{c}}{d} \cdot\left(\sigma_{1}-\sigma_{2}\right),
$$

where $M$ is the bending moment at the cross section of the retaining structure $(\mathrm{kN} \cdot \mathrm{m}), E_{c}$ is the elasticity modulus of concrete $(\mathrm{kPa}), E_{s}$ is the elasticity modulus of steel bars $(\mathrm{kPa}), I_{c}$ is the inertia moment at the cross section of the diaphragm wall $\left(\mathrm{m}^{4}\right)$. And $d$ is the center-to-center distance of a group of RSMs (m), $\sigma_{1}, \sigma_{2}$ are the stress values of a group of RSMs in tension zone and compression zone of the diaphragm wall respectively $(\mathrm{kPa})$.

\subsection{Monitoring principle}

In order to get the real force of the new composite retaining structure in the process of excavation, the south of the diaphragm wall (the depth of the excavation is $25.4 \mathrm{~m}$ ) is selected as the research object. Nine pairs of reinforcement stress meter (RSMs) were installed at nine different depths of the diaphragm wall. Two RSMs were installed on the same depth level, and they were located on the front and back rows of vertical steel bar of the diaphragm wall, totaling 18 pieces. Among them, (1)-(6), (A)-(F) RSMs are located above the basement, and its location is same 


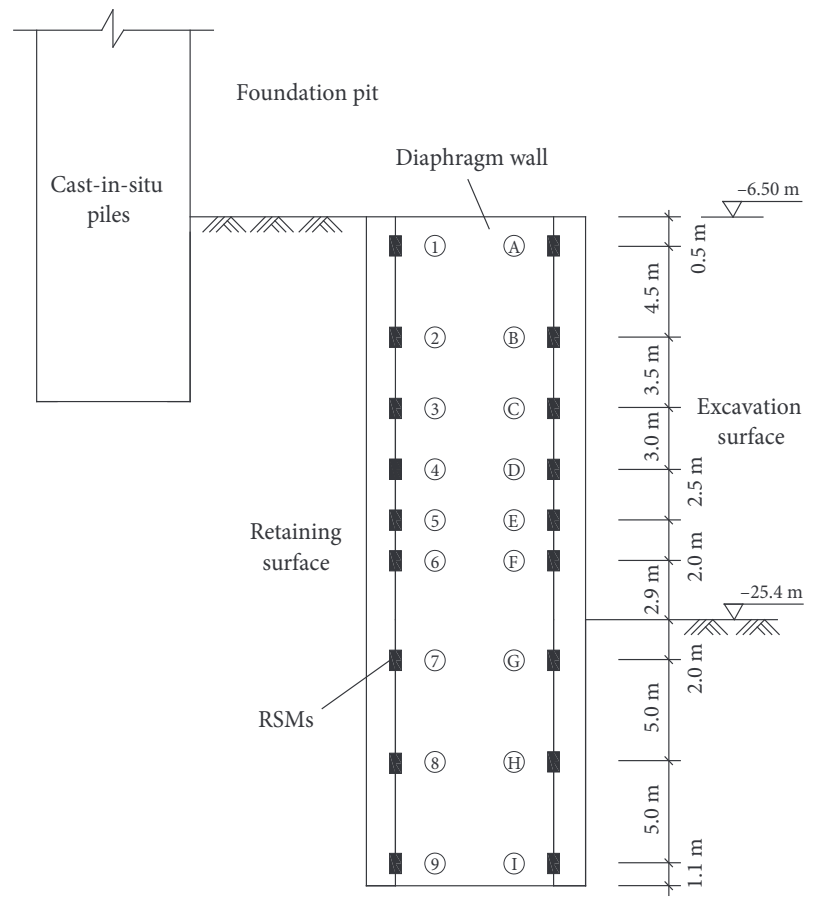

Figure 5. Schematic of installation position of rebar stress meters

as the anchor hole position; (7)-(9), (G)-(I) RSMs are located below the basement and evenly distributed. Figure 5 shows the specific installation position of the RSMs for the diaphragm wall.

\section{Finite element numerical simulation}

\subsection{Monitoring principle}

PLAXIS finite element software is a large finite element program developed by Delft University Research Center in the Netherlands, which is specially used to analyze the deformation and stability of geotechnical engineering (Zhao \& You, 2018; Zhao, Han, \& Chen, 2018; Bryson \& ZapataMedina, 2012). In this paper, PLAXIS finite element soft- ware is used to simulate the excavation process of super large and deep foundation excavations, revealing the mechanical properties of composite retaining and protection structures, and comparing the simulation results with the field measurement, as a test for the original excavation engineering design. Then, the boundary conditions are extended to simulate and analyze, as a kind of prediction and discussion for the excavation engineering after the site conditions change, to prevent accidents in the future.

All soil is considered as isotropic, continuous elastoplastic material, and the soil were assumed Mohr-Coulomb criterion. The diaphragm wall was modeled by plate elements. The anchor reinforcement is simulated by elastic element, the free part is simulated by point-to-point anchor reinforcement, and the anchorage part is simulated by elastic geogrid (Ninic, Stascheit, \& Meschke, 2014; Zhang, Chen, \& Liu, 2016; Wang, Li, Yang, Huang, \& Zhou, 2018; Wang, Li, Yang, \& Zhou, 2018). In order to simulate the interaction between retaining structure and soil more effectively and reasonably, the cohesion and internal friction angle of silty clay are reduced by the interfacial strength reduction factor Rinter. The finite element calculation model is shown in Figure 6.

\subsection{Comparison between numerical simulation and monitoring data on-site}

Firstly, the numerical simulation with the on-site monitoring data are compared and analyzed to confirm the validity of finite element calculation (Zeng, Zhang, Wang, \& $\mathrm{Li}, 2018$ ). Figure 7 is the comparative analysis of finite element output and field measured bending moment when the foundation pit is excavated to $21 \mathrm{~m}$. In the figure, the two curves are basically the same in the trend direction, and the bending moment values are basically close. It is proved that the PLAXIS finite element software is reliable in calculating the bending moment of diaphragm wall, and the constitutive model and parameters are reasonable.

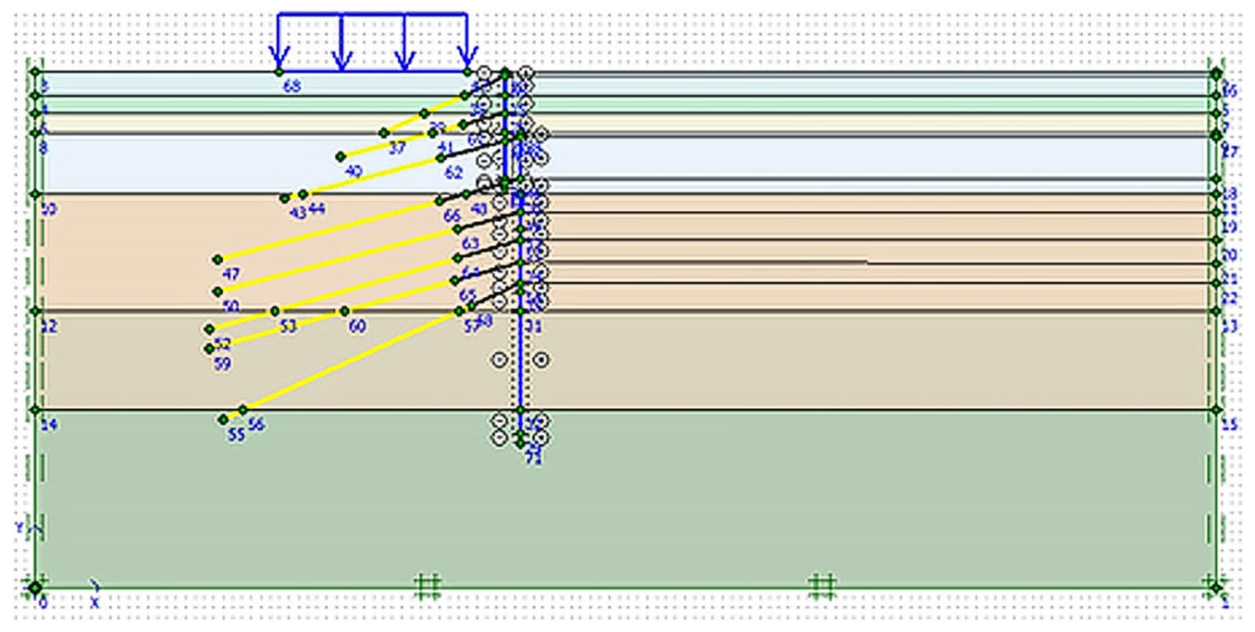

Figure 6. Calculation model 


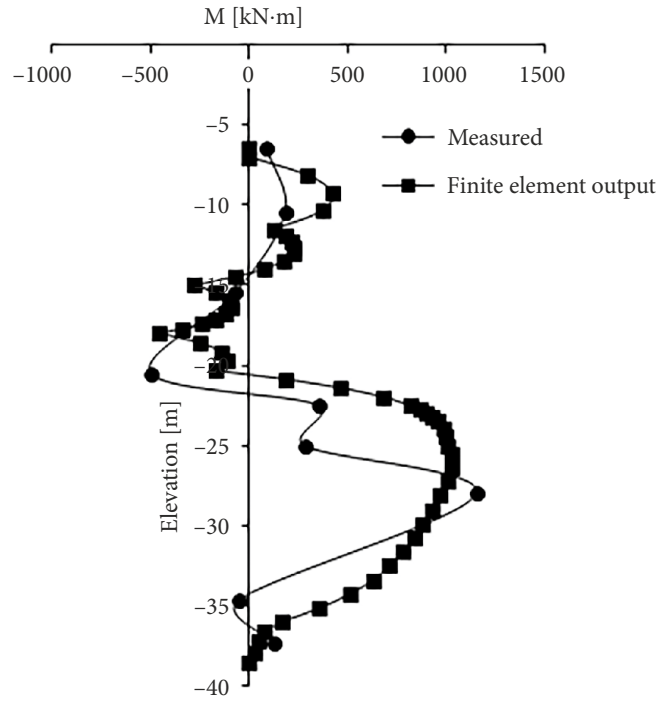

Figure 7. Comparison between finite element output and filed measured bending moment at excavation to $-21 \mathrm{~m}$

\section{Discussion}

\subsection{Numerical analysis of mechanical effect of the cast-in-situ piles}

As mentioned above, the upper part of the southern foundation pit is excavated to $-6.50 \mathrm{~m}$ under the joint support of reinforced concrete cast-in-situ pile and prestressed anchor, then the diaphragm wall supporting structure is constructed, and then the layered excavation and layered construction of prestressed anchor cable are carried out. Figure 8 simulates the bending moment evolution of reinforced concrete cast-in-situ piles after foundation pit excavation to $-6.50 \mathrm{~m}$, diaphragm wall construction, foundation pit excavation to $-7.0 \mathrm{~m}$ and the third cable tension respectively. Figure 9 shows the finite element software is used to simulate the bending moment evolution of cast-in-situ piles when the foundation pit is excavated to $-11.5 \mathrm{~m}$, and after the fourth prestressed anchors are tensioned. It can be found that the active earth pressure of the cast-in-site pile reaches the maximum when the excavation is $-6.50 \mathrm{~m}$, and the maximum bending moment is $246.7 \mathrm{kN} \cdot \mathrm{m}$. After the completion of the construction of the diaphragm wall, the maximum bending moment of the cast-in-situ pile is reduced to $226.1 \mathrm{kN} \cdot \mathrm{m}$. When the third cable is tensioned (located at the top of diaphragm wall), the maximum positive bending moment of the cast-in-situ pile is further reduced to $201.8 \mathrm{kN} \cdot \mathrm{m}$, and a negative bending moment occurs at the lower part, i.e. $-71.3 \mathrm{kN} \cdot \mathrm{m}$. This shows that the diaphragm wall and third anchor cables effectively control the internal forces and deformation of the upper supporting piles. When the foundation pit is excavated to $-11.5 \mathrm{~m}$, the excavation surface is at the same elevation as the cast-in-situ pile end. It can be found from Figure 9 that the depth of the maximum bending moment of the cast-in-situ pile is basically the same as the depth of the maximum bending moment of the pile when excavated to $-6.50 \mathrm{~m}$, which further il-

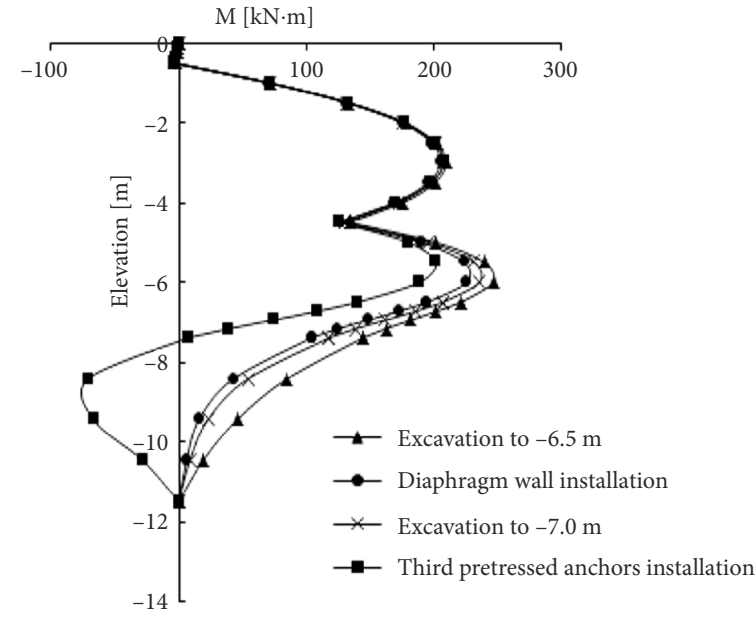

Figure 8. Evolution characteristics of cast-in-situ pile moment during excavation to $-6.5 \mathrm{~m}$ and $-7.0 \mathrm{~m}$

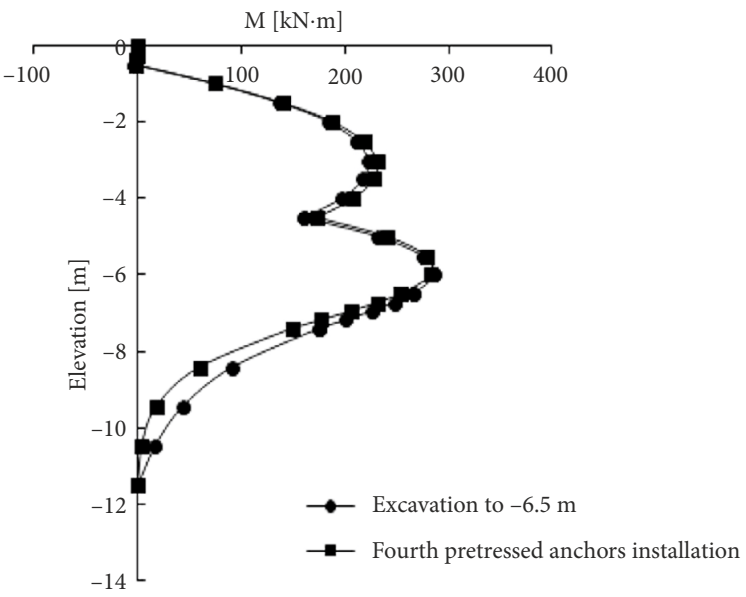

Figure 9. Evolution characteristics of bending moments of cast-in-situ piles during excavation to $-11.5 \mathrm{~m}$

lustrates the effective control of the retaining structure of the cast-in-situ pile by diaphragm wall and prestressed anchor cable.

Combining Figures 8 and 9 , it is found that the bending moment of cast-in-situ piles is not affected by diaphragm wall in the depth range of $0 \sim-4.5 \mathrm{~m}$. When the foundation pit is excavated to $-11.5 \mathrm{~m}$, the fourth prestressed anchor (that is, the second anchor cable on the diaphragm wall) has less influence on the bending moment of the cast-in-situ pile. This indicates that the range of interaction between the diaphragm wall and the soldier pile wall is limited. Therefore, during the subsequent excavation process, the bending moment of diaphragm wall is mainly affected by excavation unloading, active earth pressure and anchor tension.

\subsection{Numerical analysis of depth effect of diaphragm wall}

As shown in Figure 10, when the excavation depth of the foundation pit is $11.5 \mathrm{~m}$, the maximum bending moment of the diaphragm wall is $436.74 \mathrm{kN} \cdot \mathrm{m}$, located at $-10.38 \mathrm{~m}$. 


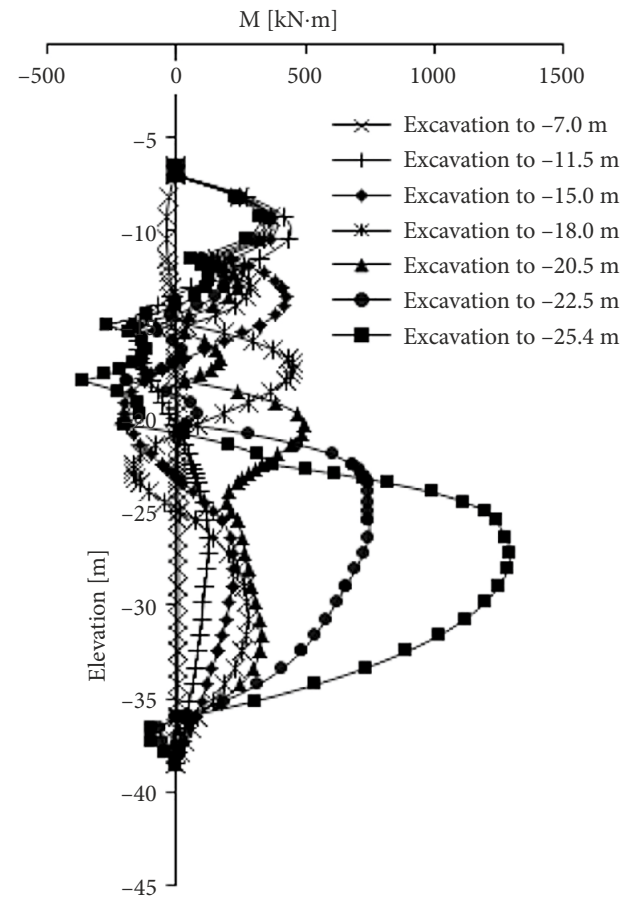

Figure 10. Influence of excavation depth on the bending moment of the diaphragm wall

When the foundation pit is excavated to $18 \mathrm{~m}$, the maximum bending moment of the diaphragm wall is $455.72 \mathrm{kN} \cdot \mathrm{m}$, which is located at $-17.41 \mathrm{~m}$. From excavation to $22.5 \mathrm{~m}$, the maximum bending moment of the diaphragm wall is $744.56 \mathrm{kN} \cdot \mathrm{m}$, which is located at $-23.97 \mathrm{~m}$. It can be seen that the maximum bending moment of the diaphragm wall is located near the excavation surface. With the increase of excavation depth, the maximum bending moment of the diaphragm wall also moves down and increases. When excavated to the design elevation, the bending moment reaches the global maximum value. This is similar to the results obtained by Yang test (Yang, Zhu, \& Guo, 2014). In addition, the position of the inflection point in each bending moment curve is consistent and coincides with the installation position of the anchor head.

\subsection{Time effect analysis of diaphragm wall}

Nine monitoring points were installed on the diaphragm wall (see Figure 5). The active earth pressure against the retaining structure on the first monitoring point is small, and the change of the bending moment of the retaining structure is not obvious. So, this point is not discussed. Among the remaining eight monitoring points, the monitoring points (3)-(C) and (5)-(E) are located in the diaphragm wall near the third and fifth rows of anchor head respectively, both are situated above the design elevation of excavation bottom. The monitoring points of No. (8)$(\mathrm{H})$ are located at depths of $7 \mathrm{~m}$ below the basement.

When the construction is carried out until the 50th day, the excavation depth is $15 \mathrm{~m}$, and the excavation surface is located at the anchor head of the 5th row of anchors. At this time, the third row of anchors on the diaphragm wall has the largest positive bending moment, reaching $325.02 \mathrm{kN} \cdot \mathrm{m}$ (see Figure 11), and the fifth row of anchors has the largest negative bending moment, reaching $-189.939 \mathrm{kN} \cdot \mathrm{m}$ (Figure 12). This shows that the bending moment of the supporting structure has a certain correlation in space and time, and the bending moment exhibits "S" type propagation.

Figure 13 shows the output of finite element and the measured bending moment of monitoring points $(8)-(\mathrm{H})$ of diaphragm wall. The measured value is larger than the simulated value. It can be seen from the diagram that the bending moment of diaphragm wall increases step by step in the early period of excavation, which indicates that the anchors can effectively control the increase of bending moment and reduce the deformation of deep diaphragm wall. In the late period of excavation, the distance between excavation face and monitoring point $(8)-(\mathrm{H})$ is getting closer and closer, and the influence of the anchors is relatively reduced, resulting in the increase rate of bending moment significantly increased.

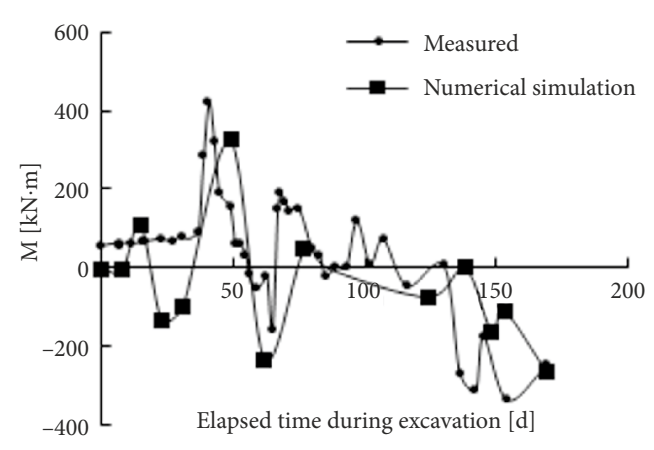

Figure 11. Comparison of the bending moments at monitoring points $(3)-(\mathrm{C})$

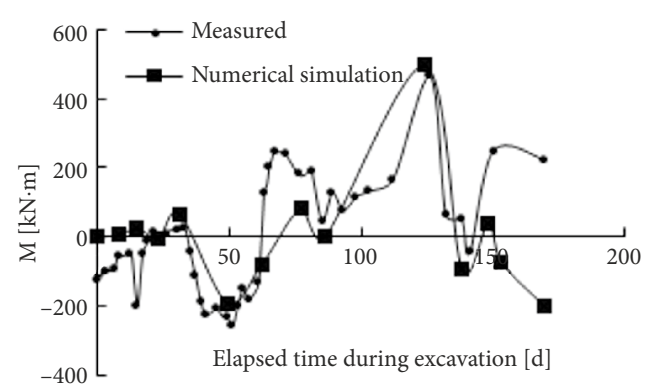

Figure 12. Comparison of the bending moments at monitoring points (5)-(E)

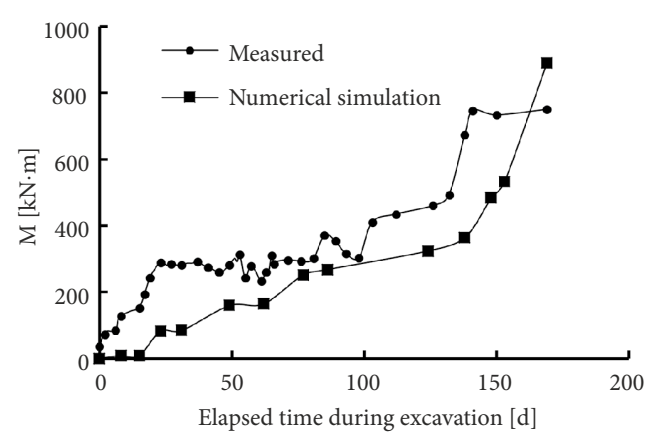

Figure 13. Comparison of the bending moments at monitoring points $(8)-(\mathrm{H})$ 
As can be seen from Figures 11, 12 and 13, the bending moment of diaphragm wall is mainly positive before the anchor is installed. After the anchor is tensioned, the bending moment of diaphragm wall decreases rapidly, and some of them becomes negative. However, when the anchor has been installed and the next layer of soil is excavated, the bending moment of the diaphragm wall becomes positive again, and the maximum value of this time is less than the maximum value before the anchor is installed. Therefore, timely tension anchor can effectively control the deformation of foundation pit. With the advance of construction process and the increase of anchor tension, the curvature of bending moment curve decreases gradually, and finally tends to be stable.

\subsection{Influence of insertion ratio}

In order to ensure the stability of foundation pit, the retaining structure must be embedded in enough depth below the excavation bottom. If the embedment depth of the retaining structure is insufficient, accidents such as instability of the retaining structure and upheaval of bottom soil may occur. However, when the embedment depth is too large, it will cause unnecessary waste of materials.

According to the excavation depth of $25.4 \mathrm{~m}$, this paper will change the plate model of the diaphragm wall in the finite element model, and the embedment depth will be changed to $7 \mathrm{~m}, 10 \mathrm{~m}, 13 \mathrm{~m}, 16 \mathrm{~m}, 19 \mathrm{~m}$ respectively, and the insertion ratio is $37.0 \% \sim 100.5 \%$. The bending moment of 5 different embedment depth of diaphragm walls is shown in Figure 14.

As shown in Figure 14, when the embedment depth of diaphragm wall is $7 \mathrm{~m}$, the negative moment is much greater than the positive moment, and the lateral displacement is much greater than the design code value. In this case, the diaphragm wall is unstable and has a greater security risk. When the embedment depth increases from $10 \mathrm{~m}$ to $19 \mathrm{~m}$, the variation of bending moment of diaphragm wall above the excavation bottom does not decrease significantly. Therefore, increasing the insertion ratio of diaphragm wall can reduce the lateral displacement, improve the stability and effectively control the deformation of foundation pit, but when the insertion ratio exceeds a certain value, the effect of controlling the deformation of diaphragm wall is not obvious.

Figure 15 shows the influence of the different embedment depth of diaphragm walls on the maximum positive bending moment. It can be found that the position of the maximum positive bending moment of the diaphragm wall moves up gradually with the increase of the embedment depth, and changes linearly. The fitting equation is as follows:

$$
Y=-0.2917 x+31.042 .
$$

The reason is that the passive earth pressure on the diaphragm wall increases with the increase of the insertion ratio and the position of the "reverse bending point" on the diaphragm wall moves up.

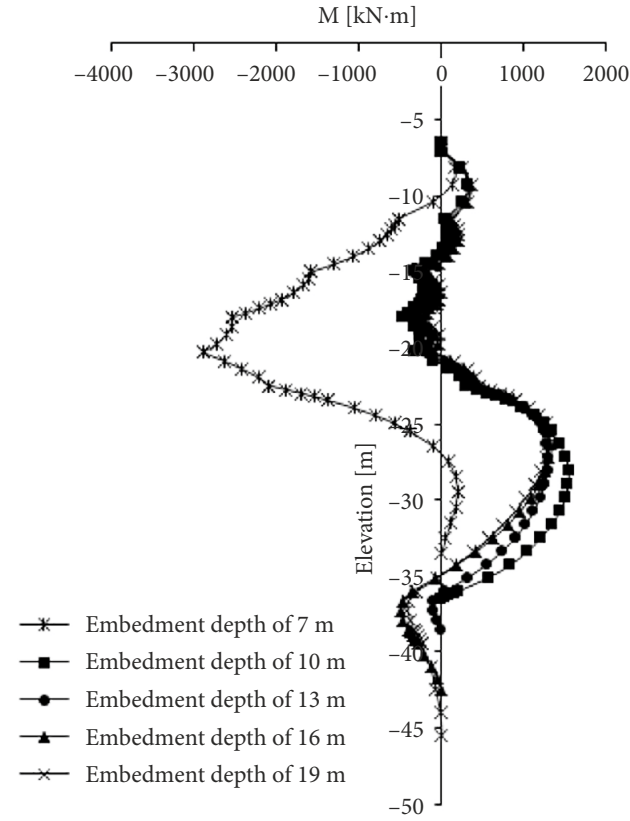

Figure 14. Influence of different insertion ratios on the bending moment

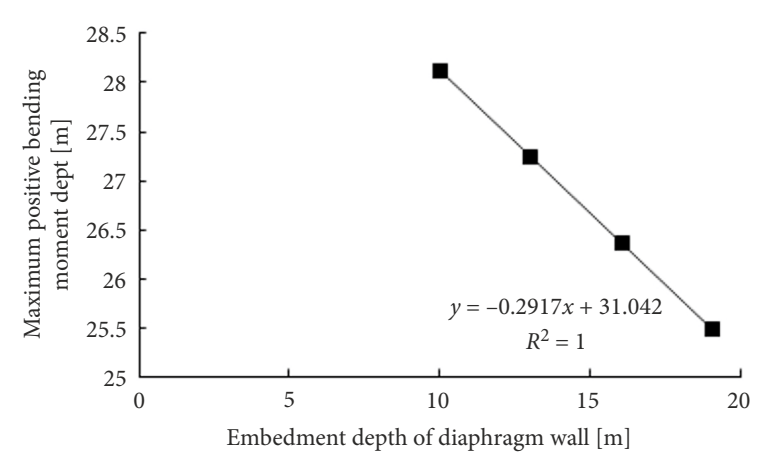

Figure 15. Effect of embedment depth on position of maximum positive moment

\subsection{Influence of the diaphragm wall rigidity}

When other conditions remain unchanged, the rigidity of the diaphragm wall in the finite element model is taken as $0.1,0.5,1,3$ and 5 times of the original rigidity parameters to analyze the influence of the rigidity change. Figure 16 shows the effect of different rigidity of the diaphragm wall on the bending moment. Figure 17 presents the effect of different rigidity of the diaphragm wall on the deformation. When the rigidity of diaphragm wall decreases from 1.0 times to 0.1 times, the bending moment of diaphragm wall above excavation bottom does not decrease obviously, but the bending moment below the bottom of foundation pit decreases obviously and the lateral displacement increases obviously. The above calculation results are consistent with the results of Faheem, Cai, and Ugai (2004). It shows that the rigidity of the diaphragm wall must meet the basic requirements to ensure the excavation safety in the process of retaining structure design.

When the rigidity of the diaphragm wall changes from 1.0 to 5.0 times, the bending moment increases obviously. 


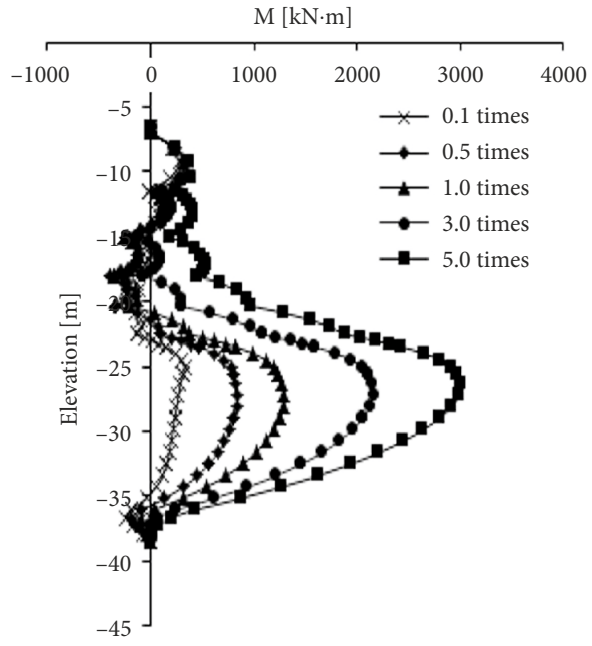

Figure 16. Effect of diaphragm wall rigidity on bending moment

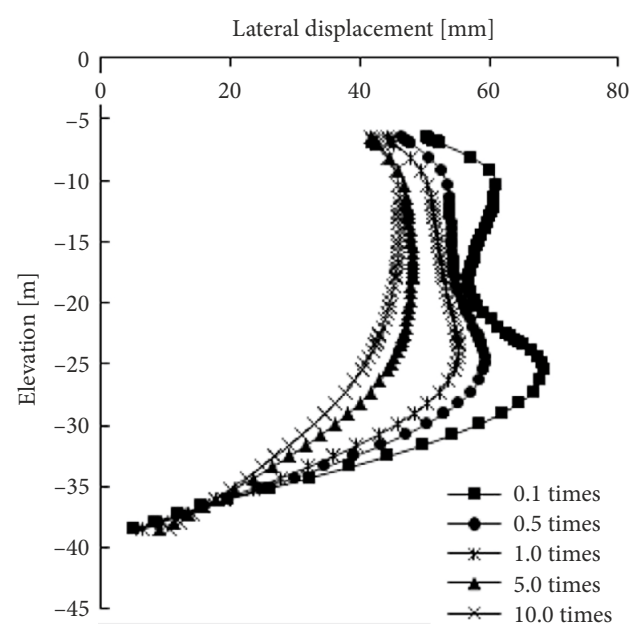

Figure 17. Effect of diaphragm wall rigidity on deformation

But the position of the maximum bending moment and the maximum lateral displacement are almost unchanged. When the rigidity increases to 10 times, the lateral displacement of the diaphragm wall is reduced. This shows that the retaining design of the project is in line with the requirements, and the excavation is safe, unrestricted increase in rigidity is of little help in controlling the deformation of foundation pit.

\subsection{Benefit analysis}

According to the geotechnical investigation report, the aquifer has a stable water level of $-7.70 \mathrm{~m} \sim-9.00 \mathrm{~m}$ in site. Therefore, the foundation pit can be supported by reinforced concrete cast-in-situ soldier pile wall within a depth of $6.5 \mathrm{~m}$, and no waterproof measures are required. For the sake of comparison, $15 \mathrm{~m}$ along the horizontal direction of the side of the foundation pit is used as a calculation unit. In a calculation unit, there are 10 reinforced concrete cast-in-situ supporting piles with a center distance of $1.5 \mathrm{~m}$. The length and diameter of each pile are $11.5 \mathrm{~m}$ and $800 \mathrm{~mm}$, and the total volume of support- ing piles is $57.8 \mathrm{~m}^{3}$. According to the construction budget price of Hainan Province in 2015, including drilling, steel bar binding and concrete pouring, etc., the total construction cost of the supporting piles in a calculation unit is about $153751.5 \mathrm{CNY}$. If a diaphragm wall is used, the wall thickness is $1.0 \mathrm{~m}$, the wall height is $6.5 \mathrm{~m}$, and the total volume of the diaphragm wall is $97.5 \mathrm{~m}^{3}$. Including all work such as groove digging, steel bar binding and concrete pouring, etc., the total construction cost of the diaphragm wall in a calculation unit is about 341071.6 CNY. It can be seen that the construction cost of the excavation with a diaphragm wall retaining structure in the range of $0 \sim-6.5 \mathrm{~m}$ is 2.2 times that of the soldier pile wall.

In addition, an extra $2.5 \mathrm{~m}$ wide construction platform is gained. In the depth range of $0 \sim-6.5 \mathrm{~m}$, the soil around the foundation pit retreats outside $2.5 \mathrm{~m}$, then the earth pressure acting on the diaphragm wall is reduced, and the horizontal displacement of the diaphragm wall is also reduced.

\section{Conclusions}

In this paper, by comparing and analyzing the field measured data and the finite element simulation results, the laws of mechanical characteristics changes of the composite retaining and protection structure in time and space are obtained. Simulation results agree generally well with the Field monitoring data. The following conclusions have been reached.

The PLAXIS finite element software can well simulate the excavation process of super large and deep foundation pit, and the bending moment output curve is in good agreement with the measured bending moment curve, which shows that the software has high reliability.

In the composite retaining and protection structure of soldier pile wall + diaphragm wall + prestressed anchor, the mutual influences range of the three supporting structures are limited.

In space, as the excavation depth increases, the maximum values of the bending moment of the diaphragm wall continuously moves down and increases, but they are located near the excavation surface and reach the global maximum when excavating to the design elevation of pit bottom. In terms of time, the bending moment of the diaphragm wall above the excavation surface is dominated by the " $\mathrm{S}$ " type, but the curvature of the bending moment curve gradually decreases with the advancement of the excavation process and the tension of the prestressed anchor, eventually tending to stable. At the early stage of excavation, the bending moment curve of the diaphragm wall below the pit bottom increased step by step. The curvature of the moment curve increases obviously during excavation to the middle and later stages.

With the increase of the insertion ratio of diaphragm wall, the position of the maximum positive bending moment moves up gradually, and the relationship between the maximum positive bending moment and the depth of the diaphragm wall is linear. The maximum bending 
moment increases to some extent with the increase of the rigidity of the diaphragm wall, but the maximum lateral displacement decreases. Increasing the rigidity and insertion ratio of diaphragm wall can effectively control the deformation of retaining structure and improve the stability. But when it reaches a certain value, the effect of controlling deformation is obviously weakened.

The composite retaining and protection structure composed of reinforced concrete cast-in-situ soldier pile wall, diaphragm wall and prestressed anchor shows good mechanical properties during the excavation process of super-large and deep foundation pit. Good economic and environmental benefits can be achieved by adopting composite support structure according to local conditions.

\section{Acknowledgements}

This work was supported by the Key R\&D Projects (the High and New Domain) of Shanxi Province in 2018 under Grant (No. 201803D121112). This support is gratefully acknowledged.

\section{Funding}

This work was supported by the Key R\&D Projects (the High and New Domain) of Shanxi Province in 2018 under Grant (No. 201803D121112).

\section{Disclosure statement}

The authors declare no any competing financial, professional, or personal interests from other parties.

\section{References}

Bryson, L. S., Zapata-Medina, D. G. (2012). Method for estimating system rigidity for excavation support walls. Journal of Geotechnical and Geoenvironmental Engineering, 138(9), 11041115. https://doi.org/10.1061/(ASCE)GT.1943-5606.0000683

Chen, J., Yang, J., Zhang, X., Wang, S., \& Ou, X. (2017). Field measurements and design optimization of diaphragm walls. Geotechnical Testing Journal, 40(1), 84-91. https://doi.org/10.1520/GTJ20160022

Cheng, X. S., Zheng, G., Diao, Y., Huang, T. M., Deng, C. H., Lei, Y. W., \& Zhou, H. Z. (2017). Study of the progressive collapse mechanism of excavations retained by cantilever contiguous piles. Engineering Failure Analysis, 71, 72-89. https://doi.org/10.1016/j.engfailanal.2016.06.011

Faheem, H., Cai, F., \& Ugai, K. (2004). Three-dimensional base stability of rectangular excavations in soft soils using FEM. Computers and Geotechnics, 31(2), 67-74. https://doi.org/10.1016/j.compgeo.2004.02.005

Hyun, S. J., Hyung, J. S., \& Yeol, S. J. (2011). A study for safety management on ground excavation by analysis of accident events. Journal of The Korea Institute for Structural Maintenance and Inspection, 15(6), 175-183.

https://doi.org/10.11112/jksmi.2011.15.6.175
Li, X. Z, Zhang, P. X, He, Z. C, Huang, Z., Cheng, M. L., \& Guo, L. (2017). Identification of geological structure which induced heavy water and mud inrush in tunnel excavation: A case study on Lingjiao tunnel. Tunnelling and Underground Space Technology, 69, 203-208. http://dx.doi.org/10.1016/j. trust. 2017.06.014

Lin, P., Liu, H., \& Zhou, W. (2015). Experimental study on failure behaviour of deep tunnels under high in-situ stresses. Tunnelling and Underground Space Technology, 46, 28-45. https://doi.org/10.1016/j.tust.2014.10.009

Liyanapathirana, D. S., \& Nishanthan, R. (2016). Influence of deep excavation induced ground movements on adjacent piles. Tunnelling and Underground Space Technology, 52, 168181. https://doi.org/10.1016 / j. tust.2015.11.019

Ninic, J., Stascheit, J., \& Meschke, G. (2014). Beam-solid contact formulation for finite element analysis of pile-soil interaction with arbitrary discretization. International Journal for Numerical and Analytical Methods in Geomechanics, 38(14), 1453-1476. https://doi.org/10.1002/nag.2262

Ooi, P. S. K., \& Ramsey, T. L. (2003). Curvature and bending moments from inclinometer data. International Journal of Geomechanics, 3(1), 64-74.

https://doi.org/10.1061/(ASCE)1532-3641(2003)3:1(64)

Szepesházi, A., Mahler, A., \& Móczár, B. (2016). Three dimensional finite element analysis of deep excavations' concave corners. Periodica Polytechnica Civil Engineering, 60(3), 371378. https://doi.org/10.3311/PPci.8608

Tan, Y., Zhu, H., Peng, F., Karlsrud, K., \& Wei, B. (2017). Characterization of semi-top-down excavation for subway station in Shanghai soft ground. Tunnelling and Underground Space Technology, 68, 244-261. https://doi.org/10.1016/j.tust.2017.05.028

Wang, J., Li, Q., Yang, C., Huang, Y., \& Zhou, C. (2018). A simple model for elastic-plastic contact of granular geomaterials. Advances in Materials Science and Engineering, Article ID 6783791. https://doi.org/10.1155/2018/6783791

Wang, J., Li, Q., Yang, C., \& Zhou, C. (2018). Repeated loading model for elastic-plastic contact of geomaterial. Advances in Mechanical Engineering, 10(7), 1-15. https://doi.org/10.1177/1687814018788778

Yang, X. H., Zhu, Y. P., \& Guo, N. 2014. Internal force test research on pile-anchor retaining structure of metro station deep foundation. Rock and Soil Mechanics, 34(2), 185-197.

Zeng, F. Y., Zhang, Z. J., Wang, J. H., \& Li, M. G. (2018). Observed performance of two adjacent and concurrently excavated deep foundation pits in soft clay. Journal of Performance of Constructed Facilities, 32(4). https://doi.org/10.1061/(ASCE)CF.1943-5509.0001184

Zhang, Z. C., Chen, Y. M., \& Liu, H. L. (2016). Numerical investigation on the impact resistance of road barriers of Micropile-MSE Wall for subgrade. Computers and Geotechnics, 82, 249-265. https://doi.org/10.1016/j.compgeo.2016.10.004

Zhao, L., \& You, G. (2018). Stability study on the northern batter of MBC Open Pit using Plaxis 3D. Arabian Journal of Geosciences, 11(6). https://doi.org/10.1007/s12517-018-3454-1

Zhao, W., Han, J. Y., \& Chen, Y. (2018). A numerical study on the influence of anchorage failure for a deep excavation retained by anchored pile walls. Advances in Mechanical Engineering, 10(2). https://doi.org/10.1177/1687814018756775 